\title{
Burden of Gastrointestinal Disease in the United States: 2012 Update
}

\author{
Anne F. Peery, MD MSCR ${ }^{1}$, Evan S. Dellon, MD MPH ${ }^{1}$, Jennifer Lund, MSPH PhD ${ }^{1}$, Seth D. \\ Crockett, MD MPH ${ }^{1}$, Christopher E. McGowan, MD ${ }^{1}$, William J Bulsiewicz, MD MSPH ${ }^{1}$, Lisa \\ M. Gangarosa, MD ${ }^{1}$, Michelle T. Thiny, MD MPH ${ }^{2}$, Karyn Stizenberg, MD1, Douglas R. \\ Morgan, MD MPH ${ }^{1}$, Yehuda Ringel, MD ${ }^{1}$, Hannah P Kim, BA ${ }^{1}$, Marco daCosta \\ DiBonaventura, $\mathrm{PhD}^{3}$, Charlotte F. Carroll, $\mathrm{MS}^{4}$, Jeffery K. Allen, $\mathrm{MA}^{4}$, Suzanne F. Cook, \\ PhD $^{4}$, Robert S. Sandler, MD MPH ${ }^{1}$, Michael D Kappelman, MD MPH ${ }^{1}$, and Nicholas J. \\ Shaheen, MD MPH ${ }^{1}$ \\ ${ }^{1}$ University of North Carolina School of Medicine, Chapel Hill, NC \\ ${ }^{2}$ Quintiles, Research, Triangle Park, NC \\ ${ }^{3}$ Kantar Health, New York, NY \\ ${ }^{4}$ Worldwide Epidemiology, GlaxoSmithKline, Research Triangle Park, NC
}

\begin{abstract}
Background \& Aims-Gastrointestinal (GI) diseases account for substantial morbidity, mortality and cost. Statistical analyses of the most recent data are necessary to guide GI research, education and clinical practice. We estimate the burden of GI disease in the US.

Methods-We collected information on the epidemiology of GI diseases (including cancers) and symptoms, along with data on resource utilization, quality of life, impairments to work and activity, morbidity, and mortality. These data were obtained from the National Ambulatory Medical Care Survey; National Health and Wellness Survey; Nationwide Inpatient Sample; Surveillance, Epidemiology, and End Results Program; National Vital Statistics System; Thompson Reuters MarketScan ${ }^{\circledR}$; Medicare; Medicaid; and the Clinical Outcomes Research Initiative's National Endoscopic Database. We estimated endoscopic use and costs and examined trends in endoscopic procedure.
\end{abstract}

\begin{abstract}
Results-Abdominal pain was the most common gastrointestinal symptom that prompted a clinic visit (15.9 million visits). Gastroesophageal reflux was the most common GI diagnosis (8.9 million visits). Hospitalizations and mortality from Clostridium difficile infection have doubled in the last 10 years. Acute pancreatitis was the most common reason for hospitalization $(274,119$ discharges). Colorectal cancer accounted for more than half of all GI cancers and was the leading cause of GI-related mortality (52,394 deaths). There were 6.9 million upper, 11.5 million lower,
\end{abstract}

\footnotetext{
(C) 2012 The American Gastroenterological Association. Published by Elsevier Inc. All rights reserved.

Corresponding Author: Nicholas J. Shaheen, MD, MPH, Professor of Medicine and Epidemiology, Director, Center for Esophageal Diseases and Swallowing, University of North Carolina School of Medicine, CB\#7080, Chapel Hill, NC 27599-7080.

Publisher's Disclaimer: This is a PDF file of an unedited manuscript that has been accepted for publication. As a service to our customers we are providing this early version of the manuscript. The manuscript will undergo copyediting, typesetting, and review of the resulting proof before it is published in its final citable form. Please note that during the production process errors may be discovered which could affect the content, and all legal disclaimers that apply to the journal pertain.

Author Contributions: AFP, ESD, MDK, RSS, NJS - conception and study design, interpretation of data, manuscript preparation. JL, SDC, CEM, WJB, LMG, MTT, KS, DRM, YR, HPK, MDD, CFC, JKA, SFC - data collection, data analysis, revision of manuscript. No conflicts of interest exist for any author.
} 
and 228,000 biliary endoscopies performed in 2009. The total cost for outpatient gastrointestinal endoscopy examinations was $\$ 32.4$ billion.

Conclusions-GI diseases are a source of substantial morbidity, mortality and cost in the US.

\section{Keywords}

Epidemiologic analysis; health services; gastrointestinal endoscopy; statistics

Gastrointestinal diseases affect an estimated 60 to 70 million Americans annually. ${ }^{1}$ In 2004, there were an estimated 4.6 million hospitalizations, 72 million ambulatory care visits and 236,000 deaths attributable to gastrointestinal disease. ${ }^{1}$ Spending on gastrointestinal diseases in the United States has been estimated at $\$ 142$ billion per year in direct and indirect costs. ${ }^{1}$

Current descriptive statistics describing the toll of gastrointestinal diseases are necessary to guide research, education and resource allocation. Reports detailing the burden of gastrointestinal disease have been published and are frequently utilized for these endeavors. ${ }^{1-6}$ With the availability of recent data and additional resources, an updated report is needed.

Our objective was to summarize from large national databases the most recent data on gastrointestinal morbidity, mortality, and cost in adults in the United States. We compiled the most recent statistics on gastrointestinal symptoms, quality of life, outpatient diagnoses, hospitalizations, cost, cancer and mortality. Because gastrointestinal endoscopy makes a major contribution to the diagnosis, management and treatment of most gastrointestinal symptoms and diseases, we also generated estimates for the current utilization and cost of gastrointestinal endoscopies in the United States. We assessed trends in endoscopic utilization and compiled indications for common gastrointestinal endoscopic procedures.

\section{Methods}

We compiled the most recently available statistics on gastrointestinal symptoms, quality of life, outpatient diagnoses, hospitalizations, cost, cancer, mortality and endoscopic utilization from a variety of publicly- and privately-held databases. We utilized limited data sets with no direct patient identifiers. Data use agreements were signed as necessary. The methods used to compile the data from the respective source database are detailed below.

\section{Symptoms and Diagnoses}

We tabulated the leading gastrointestinal symptoms and physician gastrointestinal diagnoses for outpatient clinic visits in the United States from the 2009 National Ambulatory Medical Care Survey (NAMCS). NAMCS is an annual national survey sponsored by the U.S. Centers for Disease Control and Prevention (CDC) to provide information about the use of ambulatory services by children and adults in the United States (http://www.cdc.gov/nchs/ ahcd.htm).

NAMCS collects symptom data with abstraction forms and is based on patient reported symptoms. We used the principal reason for the clinic visit in our analysis. We combined related symptoms and created a rank order list. For example, the category "gastrointestinal bleeding" includes "gastrointestinal bleeding", "blood in stool", and "vomiting blood".

NAMCS also collects physician diagnoses from pediatric and adult patient encounter forms categorized according to the International Classification of Diseases, 9th Revision (ICD-9). A maximum of three ICD-9 codes are reported. We used the primary diagnosis for the visit 
unless otherwise noted. We combined related diagnoses and created a rank order list. We excluded "special screening of malignant neoplasm of the colon" (V765.1, $\mathrm{n} \approx 1.6$ million visits) because the code does not represent a diagnosis.

\section{Quality of Life}

We report the impact of select gastrointestinal diseases and symptoms on quality of life and work and activity impairment using the 2010 United States National Health and Wellness Survey (NHWS) $(\mathrm{N}=75,000)$ (Kantar Health, New York, NY, USA). The NHWS is an annual, cross-sectional study administered by a private company to generate data on healthrelated outcomes and patient healthcare attitudes in persons eighteen years and older. The NHWS utilizes a self-administered, internet-based questionnaire. All participants complete an in-depth demographic profile and give informed consent. The NHWS uses a stratified random sample procedure to generate statistics reflective of the demographic composition of the United States, based on the March 2009 Census Bureau Current Population Survey. The prevalence estimates of conditions in the NHWS are comparable with the National Heath Interview Survey, National Health and Nutrition Examination Survey and Medical Expenditure Panel Survey. ${ }^{7-9}$

The NHWS assesses health related quality of life with the Medical Outcomes Study 12-item Short Form Survey Instrument (SF-12) ${ }^{10}$ and work and activity impairment with the Work Productivity and Activity Impairment Questionnaire in persons 18 years of age and older. ${ }^{11,12}$ We generated mean SF-12 mental and physical component scores. A lower score is associated with worse quality of life. We also generated activity and work impairment scores, which represent the percentage of health-related impairment in daily activities and work, respectively, in the past seven days. A higher percentage is associated with greater impairment. Work impairment included only participants who were employed. Participants with select diseases were identified for these analyses with the question "have you ever been diagnosed with X disease?" Participants with select symptoms were identified with the question "have you ever experienced Y symptom?" Reference diseases and symptoms have been included for comparison. Participants identified as "no disease" denied any of greater than one hundred listed diseases. Population norms for Mental and Physical Component Summary scores were derived from the scoring algorithm of the Short Form-12 version 2. Population norms for the overall work impairment and activity impairment were derived by taking the mean across the entire NHWS sample (for employed-only respondents and all respondents, respectively).

\section{Hospitalizations}

We compiled the most common inpatient gastroenterology and hepatology discharge diagnoses from the 2009 Nationwide Inpatient Sample (NIS) (http://www.hcup-us.ahrq.gov/ nisoverview.jsp). NIS was developed as part of the Healthcare Cost and Utilization Project (HCUP), a Federal-State-Industry partnership sponsored by the Agency for Healthcare Research and Quality. NIS contains data from approximately 8 million hospital stays each year in both the pediatric and adult population. NIS is the largest all-payer inpatient care database in the United States. The 2009 NIS contains all discharge data from 1,050 hospitals located in 44 States, approximating a $20 \%$ stratified sample of Unites States community hospitals. The sampling frame for the 2009 NIS is a sample of hospitals that comprises approximately $95 \%$ of all hospital discharges in the United States.

We generated rank order lists of discharge diagnoses and procedures for all patients in all hospitals. The diagnoses and procedures were categorized according to ICD-9 codes. We identified gastroenterology and hepatology diagnoses from the top 100 discharge diagnoses. We combined related discharge diagnosis codes. We created a rank order list of principal 
discharge diagnoses. We repeated this process and created a rank order list of any discharge diagnosis.

Additionally, we identified ICD-9 codes for several important gastroenterology and hepatology diagnoses not captured among the top 100 discharge diagnoses (ex. inflammatory bowel disease), and created a separate table of summary statistics for these diagnoses. Our results include both children and adults.

We performed a separate query for each individual ICD-9 code (or group of codes) to acquire data on mean and median length of stay (LOS), median costs, aggregate charges, and deaths. We estimated the total hospital days per year for all persons with each diagnosis by multiplying the number of discharges by the mean LOS. We performed a temporal analysis of the most common and select principal GI diagnoses to determine the change in discharges between 2000 and 2009.

\section{Cancer}

We tabulated gastrointestinal cancer incidence, mortality and five-year survival from the Surveillance, Epidemiology, and End Results (SEER) Program of the National Cancer Institute (www.seer.cancer.gov). The SEER program is a collection of population-based registries from 18 geographic regions in the United States including nine states, five metropolitan areas, and the Alaska Native Tumor Registry. The SEER program includes both children and adults and represents approximately twenty-six percent of the United States population. We used the most recent version of the SEER Program (April 2011), which includes survival data through 2007, and incidence data through 2008.

We gathered unadjusted gastrointestinal cancer incidence and mortality rates (per 100,000). We estimated the annual number of incident cases and deaths using the unadjusted rates, stratified by gender and age and applied to the 2010 US census population. We gathered five-year survival data and reported the proportion surviving 5-years after diagnosis and stratified by stage of disease at diagnosis.

\section{Mortality}

We tabulated the leading gastrointestinal causes of death from the National Vital Statistics System (NVSS) (http://www.cdc.gov/nchs/data_access/Vitalstatsonline.htm). NVSS is sponsored by National Center for Health Statistics with the Centers for Disease Control and Prevention. NVSS maintains an annually updated, county-level, national mortality database of children and adults with causes of death collected and reported by state registries. Causes of death are derived from death certificates and are classified by ICD-10 code. The most recent data were available from 2009.

We generated a rank order list of the most common gastrointestinal causes of death. We combined associated diagnoses to create a single, clinically meaningful entity. For example, ulcers includes ICD-10 codes for gastric ulcer (K25), duodenal ulcer (K26), peptic ulcer (K27) and gastrojejunal ulcer (K28). We calculated the crude rate per 100,000 by dividing the number of deaths listed as an underlying cause by the total US population in the United States in $2009(306,272,395)$ and multiplied by 100,000. The denominator was derived from population statistics on the CDC's Wide-ranging Online Data for Epidemiologic Research (WONDER) website (http://wonder.cdc.gov). We repeated the process and created a rank order list of deaths from selected liver diseases. Our results include both children and adults. 


\section{Endoscopic Utilization}

We generated an estimate for the prevalence and cost of upper, lower and biliary endoscopies in 2009 using the Thompson Reuters MarketScan ${ }^{\circledR}$ commercial, Medicare, and Medicaid databases. These databases contained de-identified, person-level health care claims data for all inpatient, outpatient, and pharmaceutical services for a selection of health plans. These databases included both pediatric and adult populations with the exception of Medicare. Our results include both children and adults. In our analyses limited to 2009, the total numbers of individuals in each database were 29 million, 2.7 million, and 3.5 million, respectively.

We used current procedural terminology (CPT) codes to identify all endoscopic procedures in three broad categories: upper (esophagogastroduodenoscopy (EGD), upper endoscopic ultrasound (EUS), and enteroscopy), lower (colonoscopy, flexible sigmoidoscopy, lower endoscopic ultrasound, pouch/stoma endoscopy), and biliary (endoscopic retrograde cholangiopancreatography (ERCP)). We estimated the number of procedures performed in the United States in 2009 by standardizing the number of procedures in each database to the actual age and gender distribution of the U.S. population based on 2009 census data. We determined the costs of endoscopic procedures in the United States in 2009 by summing all outpatient expenditures from the day of the procedure standardized by age and gender. Inpatient endoscopic procedure costs could not be isolated from other hospital-associated costs and were excluded from this analysis. We performed sub-analyses for common codes because the upper and lower endoscopy categories encompassed multiple procedures. The sub-analyses included EGD (diagnostic EGD, CPT 43235; and EGD with biopsy, CPT 43239) and colonoscopy (colonoscopy with biopsy, CPT 45380; and colonoscopy with polypectomy, CPT 45385).

We examined time trends in procedure volume in the three broad categories detailed above (upper, lower and biliary) from 2000-2009 in the Thompson Reuters MarketScan ${ }^{\circledR}$ commercial database.

We also examined time trends for procedures reimbursed by Medicare Part B from 2000 to 2010. Medicare Part B National Summary Data Files are available through the Centers for Medicare and Medicaid Services (http://www.cms.gov/). We used CPT codes to identify all endoscopic procedures in 5 categories - upper endoscopy, colonoscopy, endoscopic retrograde cholangiopancreatography, magnetic resonance cholangiopancreatography, and upper and lower endoscopic ultrasound. The total number of procedures performed was calculated for each category annually between 2000 and 2010 .

We compiled indications for common gastrointestinal endoscopic procedures between 2005-2010 from the Clinical Outcomes Research Initiative's (CORI) National Endoscopic Database (NED). CORI is a consortium of 108 sites from 87 practices. These practices include an adult population from private practices, academic medical centers, and government agencies (e.g. military and VA Health Services). Participating sites use a structured, computerized, report generator to process all endoscopic reports and comply with quality control requirements.

\section{Results}

\section{Symptoms and Diagnoses}

The leading gastrointestinal symptoms prompting an outpatient clinic visit in 2009 are listed in Table 1. Abdominal pain is the most common GI symptom with an estimated 15.9 million visits in 2009. Other leading symptoms at outpatient visits were diarrhea, constipation, vomiting and nausea. 
The most common physician diagnoses for gastrointestinal disorders in outpatient clinic visits in 2009 are listed in Table 2. Gastroesophageal reflux was the most frequent outpatient diagnosis with almost 9 million visits in 2009. Abdominal pain, gastroenteritis and dyspepsia, constipation, abdominal wall hernia, and diverticular disease followed in frequency.

\section{Quality of Life}

The impact of select gastrointestinal diseases and symptoms on quality of life, overall work productivity and activity impairment are detailed in Supplementary Table 1. In all diseases and symptoms for all outcomes except colorectal cancer, we found worse quality of life and significantly more work and activity impairments compared to population norms. In this survey, participants with a history of colorectal cancer are likely to be cancer survivors and these individuals demonstrate better mental health, but worse physical health, than population norms.

\section{Hospitalizations}

The most common inpatient principal gastrointestinal discharge diagnoses from 2009 are detailed in Table 3. Acute pancreatitis was the most common single gastrointestinal diagnosis and cost an estimated 2.6 billion dollars per year in inpatient costs. Combined diverticular disease (diverticulitis and hemorrhage) was actually more common than acute pancreatitis and also cost an estimated 2.6 billion dollars per year. Clostridium difficile infection discharges increased $237 \%$ since 2000 and account for a proportion of inpatient mortality similar to gastrointestinal hemorrhage (Figure 1. Panel A).

Statistics for select gastrointestinal and hepatology related discharge diagnoses not among the top 100 discharge diagnoses are detailed in Table 3. Chronic liver disease and viral hepatitis was associated with $6 \%$ mortality and cost an estimated $\$ 1.8$ billion per year in inpatient cost. Hospitalizations for nonalcoholic fatty liver disease have increased $97 \%$ since 2000. Inflammatory bowel disease and functional/motility disease both cost almost $\$ 1$ billion per year in inpatient costs.

The most common inpatient gastrointestinal and hepatology related discharge diagnoses among any listed diagnoses from 2009 are detailed in Supplementary Table 2. Esophageal reflux (4.4 million), obesity (1.7 million) and constipation ( 1 million) were the most common discharge diagnoses.

\section{Cancer}

Gastrointestinal cancer incidence, mortality, and five-year survival are detailed in Table 4. An estimated 147,308 people were diagnosed with colorectal cancer in the United States in 2008. When diagnosed with localized disease, five-year survival is $90 \%$. Esophageal, pancreatic and liver cancer are less common but are associated with five-year survival of less than $40 \%$ even when diagnosed at an early stage.

\section{Mortality}

In 2009, there were a total of 2,437,163 deaths in the United States with 245,921 attributable to an underlying gastrointestinal cause (10\%). The leading gastrointestinal causes of death are presented in Table 5. Colorectal cancer remains the leading gastrointestinal cause of mortality followed by pancreatic and hepatobiliary neoplasms. Clostridium difficile is now the $9^{\text {th }}$ leading gastrointestinal cause of death, increasing from 2,195 deaths in 2002 to 7,251 in 2009 , a $230 \%$ absolute increase. 
In 2009, there were 30,558 deaths in the United States attributed to chronic liver disease and cirrhosis, representing the $12^{\text {th }}$ leading cause overall. Malignant neoplasms of the liver and biliary tree represent the most frequent cause of hepatic and biliary mortality, followed by cirrhosis/fibrosis, alcoholic liver disease, and chronic hepatitis $\mathrm{C}$ virus infection (Table 5). Mortality rates associated with each of these causes of death have increased since 2002, whereas the rates attributable to acute and chronic hepatitis B and primary biliary cirrhosis have remained stable.

\section{Endoscopic Utilization}

There were an estimated 6.9 million upper, 11.5 million lower, and 228,000 biliary endoscopies performed in the United States in 2009 based on Thompson Reuters MarketScan ${ }^{\circledR}$ commercial, Medicare, and Medicaid databases. The estimated total outpatient cost was $\$ 32.4$ billion. Upper endoscopies were estimated at $\$ 12.3$ billion, lower endoscopies \$19.2 billion and ERCP \$900 million. The estimated average costs for all upper endoscopies, lower endoscopies, and ERCPs were $\$ 1,775,1,672$, and $\$ 3,899$, respectively. The estimated average total cost for EGD alone (either diagnostic or with biopsy) was $\$ 685$. The estimated average total cost for colonoscopy alone (either with biopsy or with polypectomy) was $\$ 1,013$.

The trends in endoscopic volume in commercially insured patients in the United States between 2000 and 2009 are detailed in Figure 2 Panel B. We found a 54\% and 17\% increase in all upper and lower GI endoscopy, respectively, but a 16\% decrease in ERCP.

Additionally, the trends in endoscopic volume in Medicare Part B in the United States between 2000 and 2010 are detailed in Table 6. Overall, there was also a significant increase in the performance of endoscopic procedures in Medicare recipients over the last decade. Colonoscopy is consistently the most commonly performed procedure with over 3.3 million colonoscopies performed in Medicare beneficiaries in 2010. While the use of MRCP was significantly lower than that of ERCP in 2000, there has been a nearly 8-fold increase in its use, making it more than twice as common as ERCP in 2010. EUS utilization has increased 6-fold in the last ten years.

A total of 785,302 colonoscopies, 34,884 flexible sigmoidoscopies, 448,888 EGDs, 16,980 ERCPs, and 13,374 EUSs were recorded in CORI-NED from 2005-2010. The most common indications for upper endoscopy were reflux symptoms (24\%), dysphagia (20\%), evaluation for any GI bleeding symptom (19\%), and abdominal pain or bloating (18\%) (Supplementary Table 3). The most common indications for colonoscopy were routine screening exams (32\%), evaluation of any GI bleeding symptom (22\%), and surveillance for adenomatous polyps (18\%) (Supplementary Table 4).

\section{Discussion}

As detailed above, the toll of gastrointestinal and liver disease on the U.S. population is extensive. Using the most comprehensive statistical resources available, we present a broad and detailed picture of the current challenges facing these patients and our specialty. Several trends merit special mention.

The toll of $C$. difficile infection is large and becoming more prominent. $C$. difficile hospitalizations have increased by $237 \%$ since 2000 . This finding is consistent with the documented increase in $C$. difficile incidence in the United States. ${ }^{13-15}$ In-hospital mortality attributable to $C$. difficile is estimated at $4 \%$, which is comparable to the 30 day estimate of $6 \%{ }^{16} C$. difficile is now the $9^{\text {th }}$ leading gastrointestinal cause of death. 
We also found that $C$. difficile infection was associated with marked impairment in quality of life and capacity for activity. These data may actually represent an under-estimate of the association of this infection with diminished quality of life, given that some proportion of the participants in the NHWS had resolved disease. Whether those with resolved disease also have impaired quality of life and activity impairment is unknown.

Hospitalizations for morbid obesity increased by $314 \%$ since 2000 . While the prevalence of obesity between 1998 and 2008 was relatively stable, the prevalence of morbid obesity has increased significantly. ${ }^{17}$ Bariatric surgical procedures also increased, from 13,000 in 1998 to more than 100,000 in 2003 , and this may account for some portion of the observed trend. ${ }^{18}$

Reflux symptoms remain the most common indication for upper endoscopy, and gastroesophageal reflux disease the most common principal gastroenterology-related diagnosis in the primary care setting. Barrett's esophagus accounted for almost a half million visits in 2009. An estimated 3.3 million Americans have a diagnosis of Barrett's esophagus. ${ }^{19}$ Most (90\%) patients with Barrett's esophagus have nondysplastic disease. ${ }^{20}$ Guidelines generally recommend that patients with nondysplastic disease undergo endoscopic surveillance every three to five years. Given the large number of subjects with Barrett's, these examinations represent a substantial commitment of resources.

An estimated 147,308 people were diagnosed with colorectal cancer in the United States in 2008. Colorectal cancer continues to be the number one cause of GI-related mortality. Colorectal cancer accounts for more than half of all GI cancer diagnoses and a third of GI cancer-related deaths.

There is no single national endoscopic database to estimate the prevalence and cost of endoscopy. We generated our estimates using a mix of public and private databases. Total outpatient cost for gastrointestinal endoscopy in 2009 was $\$ 32.4$ billion. Our estimate is higher than a previous estimate ${ }^{1}$ and suggests that the cost of gastrointestinal endoscopy is not well characterized. Our estimate is likely a more accurate approximation because we utilized health care claims data from 35 million people in a mix of public and private databases and standardized the estimates of procedures performed to the US population based on census data.

We estimated that 6.9 million upper, 11.5 million lower, and 228,000 biliary endoscopies were performed in the United States in 2009. A survey published in 2000 estimated that 5 million flexible sigmoidoscopies and 4 million colonoscopies were performed that year in the United States. ${ }^{21}$ A second survey in 2002 estimated that approximately 2.8 million flexible sigmoidoscopies and 14.2 million colonoscopies were performed. ${ }^{22}$ No recent estimates on upper endoscopies or biliary endoscopies have been published. Our data demonstrate that ERCP volume has increased more slowly than that of other endoscopic procedures. Concurrently, the use of MRCP has increased dramatically, perhaps due to the expanded role of MRCP in the diagnosis of pancreaticobiliary disorders and the decreased use of ERCP for purely diagnostic indications.

Our findings should be viewed in light of the strengths and limitations of the databases from which we gathered the data. NAMCS data are based on office-based physician visits and do not reflect other important sources of ambulatory care including the emergency department, urgent care and federal facilities. The strength of NAMCS is that the diagnoses and patient symptoms are extracted from the medical record using a standardized procedure. The NHWS is an Internet based survey. Diagnoses are not verified and it is possible that those who respond are systematically different then those who do not complete the survey. Despite these limitations, NHWS is a large nationally representative sample comparable 
with the National Heath Interview Survey. ${ }^{7}$ Not all states contribute to NIS. Cost estimates are approximated from charges and do not include physician fees. Regardless, NIS is the largest all-payer inpatient data source in the United States and contains charge information on all patients. SEER data represents 18 areas of the country. While the data are weighted to approximate national estimates they are not statistically representative. SEER data are verified and data are estimated to be 99 percent complete from contributing sites. The National Vital Statistics System is a complete accounting of deaths in the United States but is dependent on the accuracy of death certificates, and coding of death certificates may be erroneous. Inpatient endoscopic procedure costs could not be isolated from other hospitalassociated costs and were excluded from this analysis. CORI data are based on voluntary participation and are not nationally representative. . Finally, our ability to detect conditions that cause substantial burden of disease depends on codes that may be imprecise, poorly used, or non-existent. Non-alcoholic fatty liver disease, for example, is prevalent but is newly recognized and therefore poorly captured with codes. For this reason, updated reports will be needed as more recent data becomes available.

In summary, we present a comprehensive and current estimate of the toll of gastrointestinal and liver diseases in the U.S. Payers, policymakers, clinicians, and others interested in resource utilization may use these statistics to better understand evolving disease trends, and the best way to meet the challenge of these diseases.

\section{Supplementary Material}

Refer to Web version on PubMed Central for supplementary material.

\section{Acknowledgments}

Grant Support: This research was supported in part by a grant from the National Institutes of Health (T32 DK07634). Selected data in this manuscript were obtained from the Clinical Outcomes and Research Initiative National Endoscopic Database (CORI-NED), with support from National Institutes of Health (NIDDK) U01DK57132-01. In addition, CORI has received support from the following entities to support the infrastructure of the practice-based network: AstraZeneca, Novartis, Bard International, Pentax USA, ProVation, Endosoft, GIVEN Imaging, and Ethicon. The commercial entities had no involvement in this research.

\section{References}

1. Everhart JE, Ruhl CE. Burden of digestive diseases in the United States part I: overall and upper gastrointestinal diseases. Gastroenterology. 2009; 136:376-386. [PubMed: 19124023]

2. Sandler RS, Everhart JE, Donowitz M, Adams E, Cronin K, Goodman C, Gemmen E, Shah S, Avdic A, Rubin R. The burden of selected digestive diseases in the United States. Gastroenterology. 2002; 122:1500-1511. [PubMed: 11984534]

3. Russo MW, Wei JT, Thiny MT, Gangarosa LM, Brown A, Ringel Y, Shaheen NJ, Sandler RS. Digestive and liver diseases statistics, 2004. Gastroenterology. 2004; 126:1448-1453. [PubMed: 15131804]

4. Shaheen NJ, Hansen RA, Morgan DR, Gangarosa LM, Ringel Y, Thiny MT, Russo MW, Sandler RS. The burden of gastrointestinal and liver diseases, 2006. Am J Gastroenterol. 2006; 101:21282138. [PubMed: 16848807]

5. Everhart JE, Ruhl CE. Burden of digestive diseases in the United States part II: lower gastrointestinal diseases. Gastroenterology. 2009; 136:741-754. [PubMed: 19166855]

6. Everhart JE, Ruhl CE. Burden of digestive diseases in the United States Part III: Liver, biliary tract, and pancreas. Gastroenterology. 2009; 136:1134-1144. [PubMed: 19245868]

7. Bolge SC, Doan JF, Kannan H, Baran RW. Association of insomnia with quality of life, work productivity, and activity impairment. Qual Life Res. 2009; 18:415-422. [PubMed: 19288223] 
8. DiBonaventura MD, Wagner JS, Yuan Y, L'Italien G, Langley P, Ray Kim W. Humanistic and economic impacts of hepatitis C infection in the United States. J Med Econ. 2010; 13:709-718. [PubMed: 21091098]

9. Finkelstein EA, Allaire BT, DiBonaventura MD, Burgess SM. Direct and indirect costs and potential cost savings of laparoscopic adjustable gastric banding among obese patients with diabetes. J Occup Environ Med. 2011; 53:1025-1029. [PubMed: 21866052]

10. Ware, JEKM.; Turner-Bowker, DM., et al. How to score version 2 of the SF-12 Health Survey (with a supplement documenting version 1). Lincoln, RI: QualityMetric Incorporated; 2002.

11. Reilly MC, Zbrozek AS, Dukes EM. The validity and reproducibility of a work productivity and activity impairment instrument. Pharmacoeconomics. 1993; 4:353-365. [PubMed: 10146874]

12. Prasad M, Wahlqvist P, Shikiar R, Shih YC. A review of self-report instruments measuring healthrelated work productivity: a patient-reported outcomes perspective. Pharmacoeconomics. 2004; 22:225-244. [PubMed: 14974873]

13. Archibald LK, Banerjee SN, Jarvis WR. Secular trends in hospital-acquired Clostridium difficile disease in the United States, 1987-2001. J Infect Dis. 2004; 189:1585-1589. [PubMed: 15116293]

14. McDonald LC, Owings M, Jernigan DB. Clostridium difficile infection in patients discharged from US short-stay hospitals, 1996-2003. Emerg Infect Dis. 2006; 12:409-415. [PubMed: 16704777]

15. Ricciardi R, Rothenberger DA, Madoff RD, Baxter NN. Increasing prevalence and severity of Clostridium difficile colitis in hospitalized patients in the United States. Arch Surg. 2007; 142:624-631. discussion 631. [PubMed: 17638799]

16. Karas JA, Enoch DA, Aliyu SH. A review of mortality due to Clostridium difficile infection. J Infect. 2010; 61:1-8. [PubMed: 20361997]

17. Sturm R. Increases in morbid obesity in the USA; 2000-2005. Public Health. 2007; 121:492-496. [PubMed: 17399752]

18. Santry HP, Gillen DL, Lauderdale DS. Trends in bariatric surgical procedures. JAMA. 2005; 294:1909-1917. [PubMed: 16234497]

19. Sampliner RE. A population prevalence of Barrett's esophagus--finally. Gastroenterology. 2005; 129:2101-2103. [PubMed: 16344076]

20. Hirota WK, Loughney TM, Lazas DJ, Maydonovitch CL, Rholl V, Wong RK. Specialized intestinal metaplasia, dysplasia, and cancer of the esophagus and esophagogastric junction: prevalence and clinical data. Gastroenterology. 1999; 116:277-285. [PubMed: 9922307]

21. Brown ML, Klabunde CN, Mysliwiec P. Current capacity for endoscopic colorectal cancer screening in the United States: data from the National Cancer Institute Survey of Colorectal Cancer Screening Practices. Am J Med. 2003; 115:129-133. [PubMed: 12893399]

22. Seeff LC, Manninen DL, Dong FB, Chattopadhyay SK, Nadel MR, Tangka FK, Molinari NA. Is there endoscopic capacity to provide colorectal cancer screening to the unscreened population in the United States? Gastroenterology. 2004; 127:1661-1669. [PubMed: 15578502] 
PANEL A

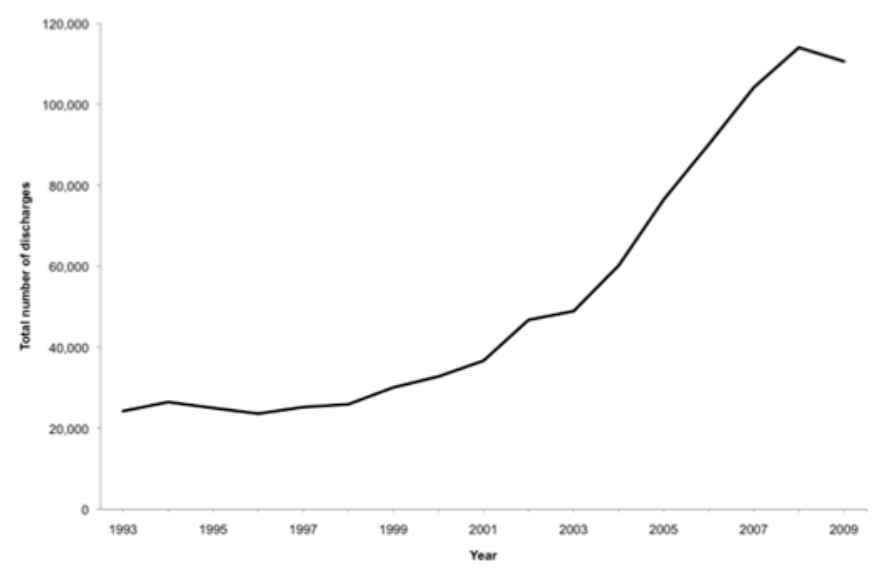

PANEL B

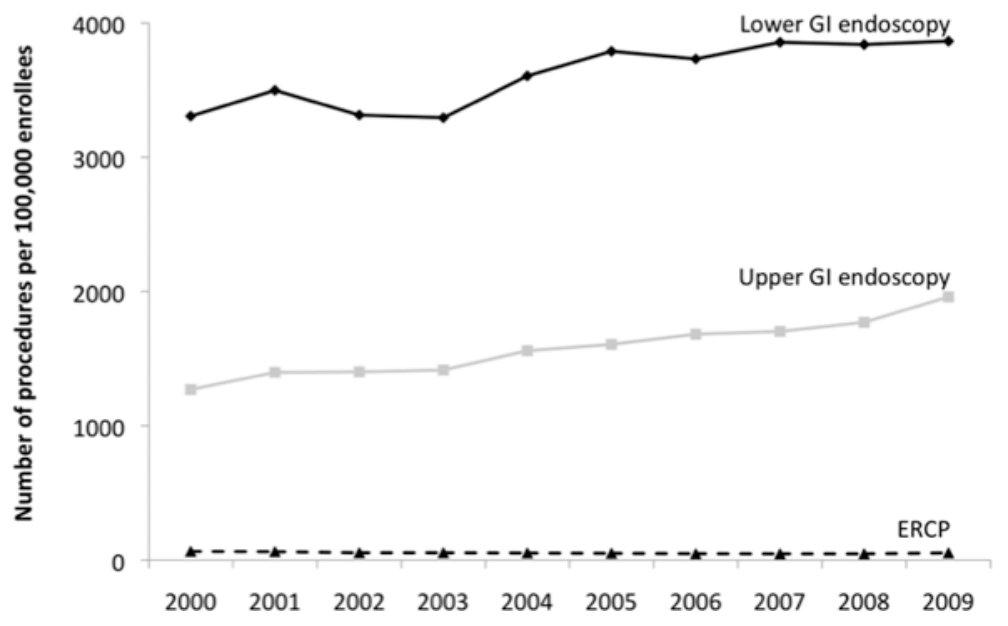

Figure 1.

Panel A: Number of annual hospital discharges with a principal diagnosis of $C$. difficile infection, 1993-2009, from the National Inpatient Sample

Figure 1. Panel B: Time trends in endoscopy procedure rates in commercially insured patients in the United States, 2000-2009. Upper GI endoscopy included esophagogastroduodenoscopy, upper endoscopic ultrasound, and enteroscopy. Lower GI endoscopy included colonoscopy, flexible sigmoidoscopy, lower endoscopic ultrasound, and pouch/stoma endoscopy. 
Table 1

Leading Gastrointestinal Symptoms Prompting an Outpatient Clinic Visit, 2009*

\begin{tabular}{llr} 
Rank & Symptom & $\begin{array}{r}\text { Estimated } \\
\text { visits }\end{array}$ \\
\hline 1 & Abdominal pain & $15,863,956$ \\
2 & Diarrhea & $4,236,051$ \\
3 & Constipation & $3,175,842$ \\
4 & Vomiting & $2,861,790$ \\
5 & Nausea & $2,814,364$ \\
6 & Heartburn and indigestion & $1,982,517$ \\
7 & Rectal bleeding & $1,702,331$ \\
8 & Other GI symptoms, unspecified & $1,357,602$ \\
9 & Dysphagia & $1,148,041$ \\
10 & Gastrointestinal bleeding & $1,073,771$ \\
11 & Appetite decrease & 725,705 \\
12 & Bloating and distention & 699,928 \\
13 & Anorectal symptoms (including incontinence) & 520,772 \\
14 & Symptoms related to the liver and biliary system & 454,355 \\
\hline
\end{tabular}

2009 National Ambulatory Medical Care Survey (http://www.cdc.gov/nchs/ahcd.htm). 
Table 2

Leading Physician Diagnoses for Gastrointestinal Disorders in Outpatient Clinic Visits in the United States, $2009^{*}$

\begin{tabular}{rlcl} 
Rank & Diagnosis & Estimated visits & ICD-9 Codes \\
\hline 1 & GERD $^{\dagger}$ & $8,863,568$ & $530.11,530.81$ \\
2 & Abdominal pain & $7,170,332$ & $389.04,789.00,789.06,789.07,789.09$ \\
3 & Gastroenteritis and dyspepsia & $4,007,198$ & $008.8,535.50,536.8$ \\
4 & Constipation & $3,980,438$ & 564.00 \\
5 & Abdominal wall hernia & $3,559,932$ & $550.90,553.10,553.20$ \\
6 & Diverticular disease & $2,682,168$ & $562.10,562.11$ \\
7 & Diarrhea & $2,402,350$ & 787.91 \\
8 & Inflammatory bowel disease & $1,893,799$ & $555.9,556.9$ \\
9 & Colorectal neoplasm & $1,744,089$ & $153.9,154.0,154.1,211.3$ \\
10 & Nausea and vomiting & $1,678,515$ & $787.02,787.03$ \\
11 & Rectal bleeding & $1,667,653$ & $569.3,578.1$ \\
12 & Irritable colon & $1,550,072$ & 564.1 \\
13 & Hepatitis C infection & $1,230,420$ & $070.54,070.70$ \\
14 & Hemorrhoids & $1,071,430$ & $455.0,455.4,455.6,455.8$ \\
15 & Dysphagia & $1,020,743$ & 787.20 \\
16 & Appendicitis & 663,930 & 541.0 \\
17 & Cirrhosis of liver & 635,463 & 571.5 \\
18 & Barrett s esophagus & 440,605 & 530.85 \\
19 & Hepatitis, unspecified & 379,062 & 573.3 \\
20 & Gallstone disease & 303,606 & 547.10 \\
\hline
\end{tabular}

*2009 National Ambulatory Medical Care Survey (http://www.cdc.gov/nchs/ahcd.htm).

GERD also includes visits with a primary diagnosis of diaphragmatic hernia (553.3) and a secondary diagnosis code of Esophageal reflux (530.81).

${ }^{*}$ Gastroenteritis and dyspepsia also includes visits with a primary diagnosis of diaphragmatic hernia (553.3), but without a secondary diagnosis code of Esophageal reflux (530.81). 


\begin{tabular}{|c|c|c|c|c|c|c|c|c|c|c|c|c|c|c|}
\hline 焉 & 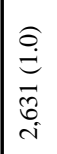 & 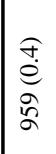 & $\begin{array}{l}0 \\
0 \\
e \\
\tilde{n} \\
\\
-1\end{array}$ & $\begin{array}{l}\text { fे } \\
\stackrel{0}{0} \\
\&\end{array}$ & 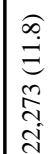 & 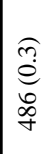 & $\begin{array}{l}\tilde{n} \\
\stackrel{5}{a} \\
\dot{\sigma} \\
\sigma \\
\dot{\sigma}\end{array}$ & $\begin{array}{l}\widehat{\vec{d}} \\
\stackrel{d}{d} \\
\stackrel{d}{d} \\
i\end{array}$ & $\begin{array}{l}\widehat{\vec{e}} \\
\stackrel{\vec{m}}{a}\end{array}$ & $\begin{array}{l}\hat{\oplus} \\
\infty \\
\infty \\
0 \\
o \\
\dot{f}\end{array}$ & 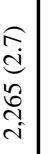 & $\begin{array}{l}\widehat{\overbrace{}} \\
\stackrel{\theta}{0} \\
\infty \\
\varrho\end{array}$ & $\stackrel{\infty}{\stackrel{\infty}{\Xi}}$ & $\mid \begin{array}{l}\hat{\bar{e}} \\
\stackrel{m}{r}\end{array}$ \\
\hline 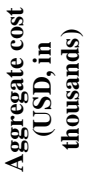 & 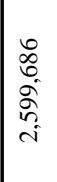 & $\begin{array}{l}\vec{n} \\
\hat{n} \\
\alpha \\
\hat{n} \\
\hat{c}\end{array}$ & 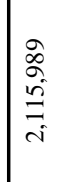 & 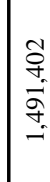 & $\begin{array}{l}\text { ते } \\
\text { ते } \\
\text { त̂ं } \\
\text { ind }\end{array}$ & 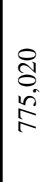 & $\begin{array}{l}\vec{a} \\
\hat{n} \\
= \\
=\end{array}$ & $\begin{array}{l}\hat{q} \\
f \\
\infty \\
\stackrel{\sigma}{\sigma} \\
-\end{array}$ & $\begin{array}{l}\text { רิ } \\
\text { î } \\
\text { ț }\end{array}$ & $\begin{array}{l}\stackrel{m}{\sim} \\
\stackrel{=}{\Xi} \\
=\end{array}$ & 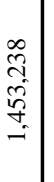 & 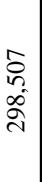 & $\begin{array}{l}\text { ते } \\
\text { ळ } \\
\infty\end{array}$ & 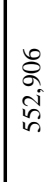 \\
\hline
\end{tabular}

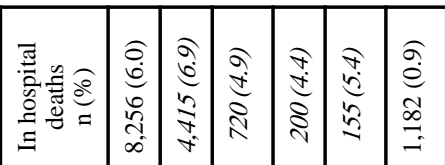

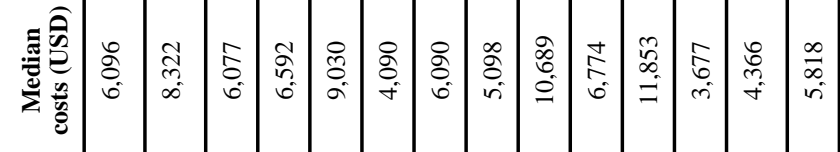

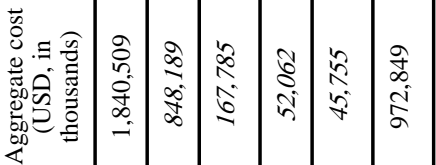

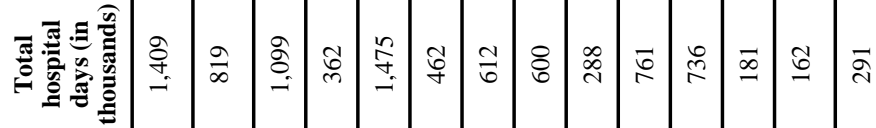

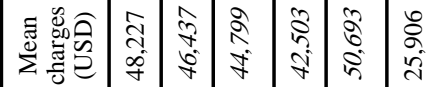

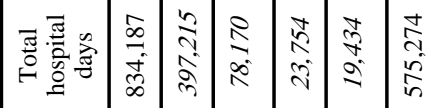

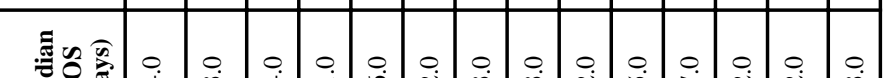

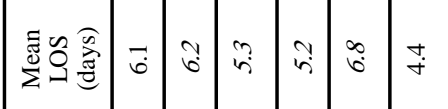

$\begin{array}{ll}Z & \\ \frac{1}{1} & \\ 0 & 0 \\ D & 0 \\ D & \frac{0}{0} \\ \frac{10}{5} & \end{array}$

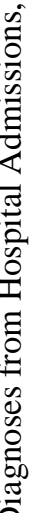

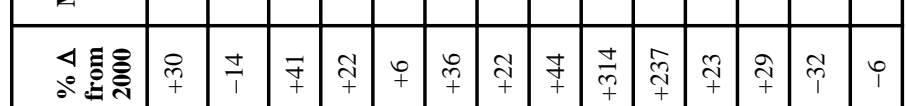

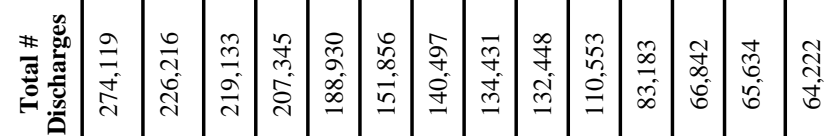

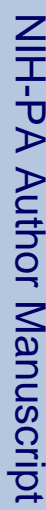

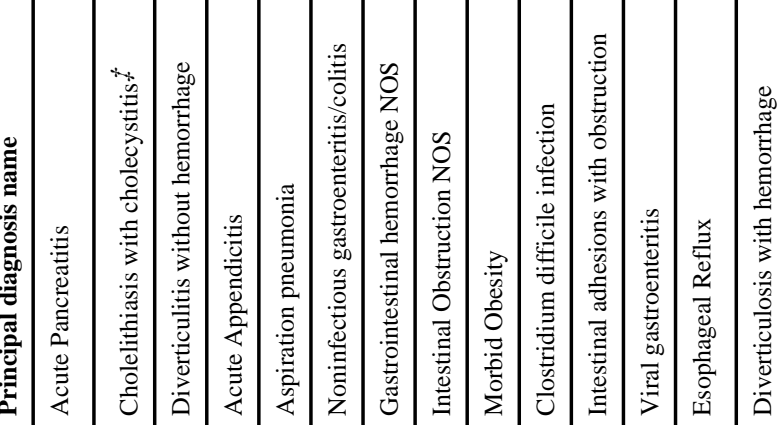

즐

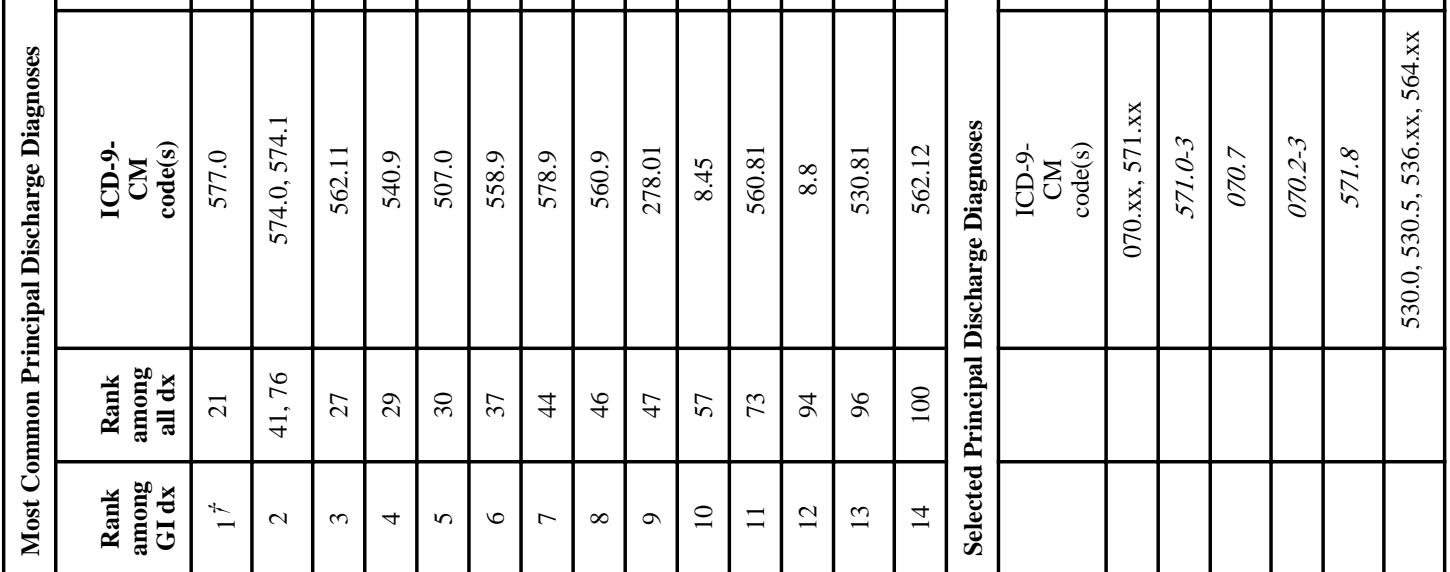




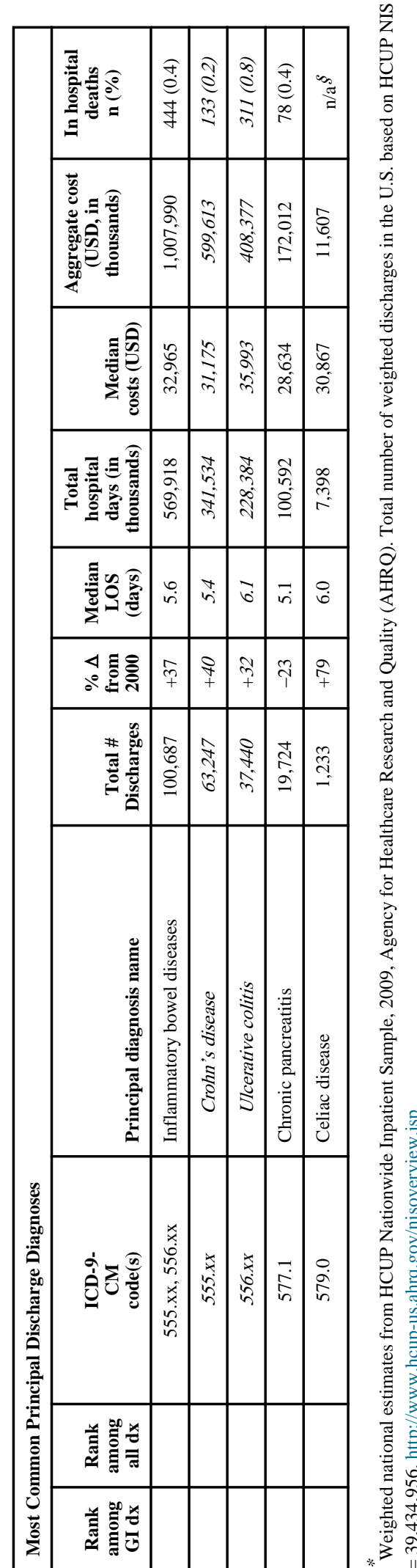

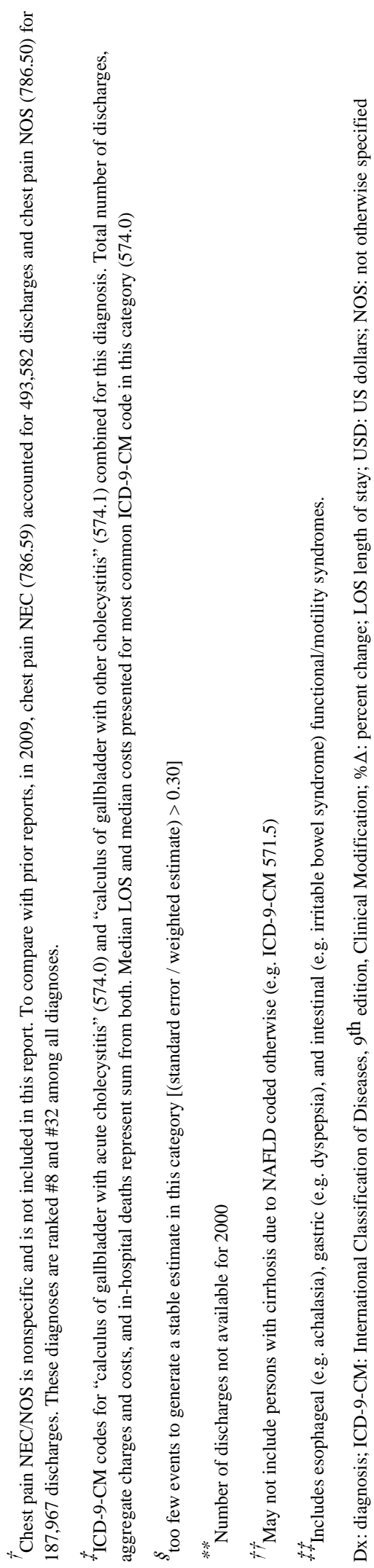




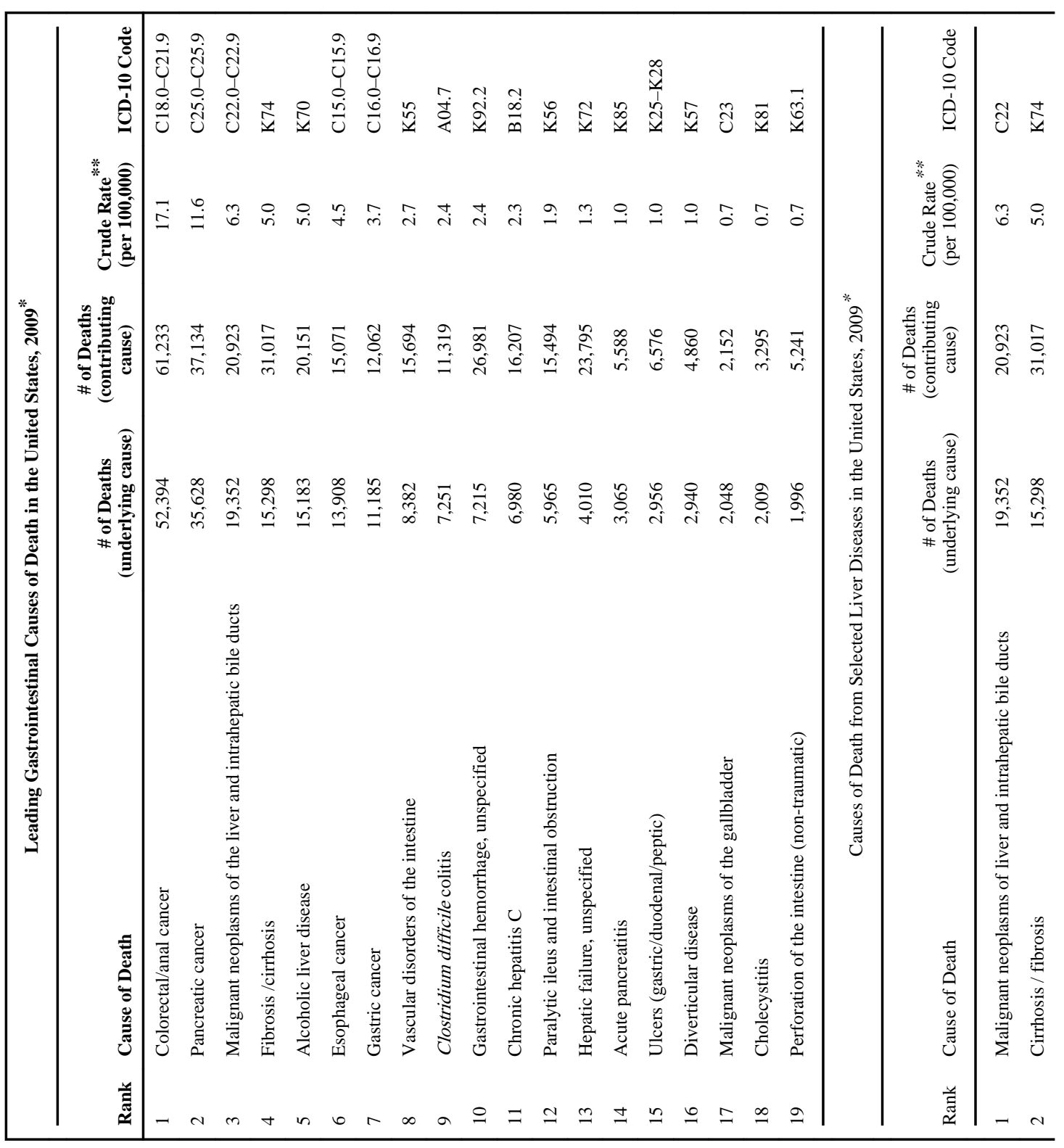

Gastroenterology. Author manuscript; available in PMC 2013 November 01. 


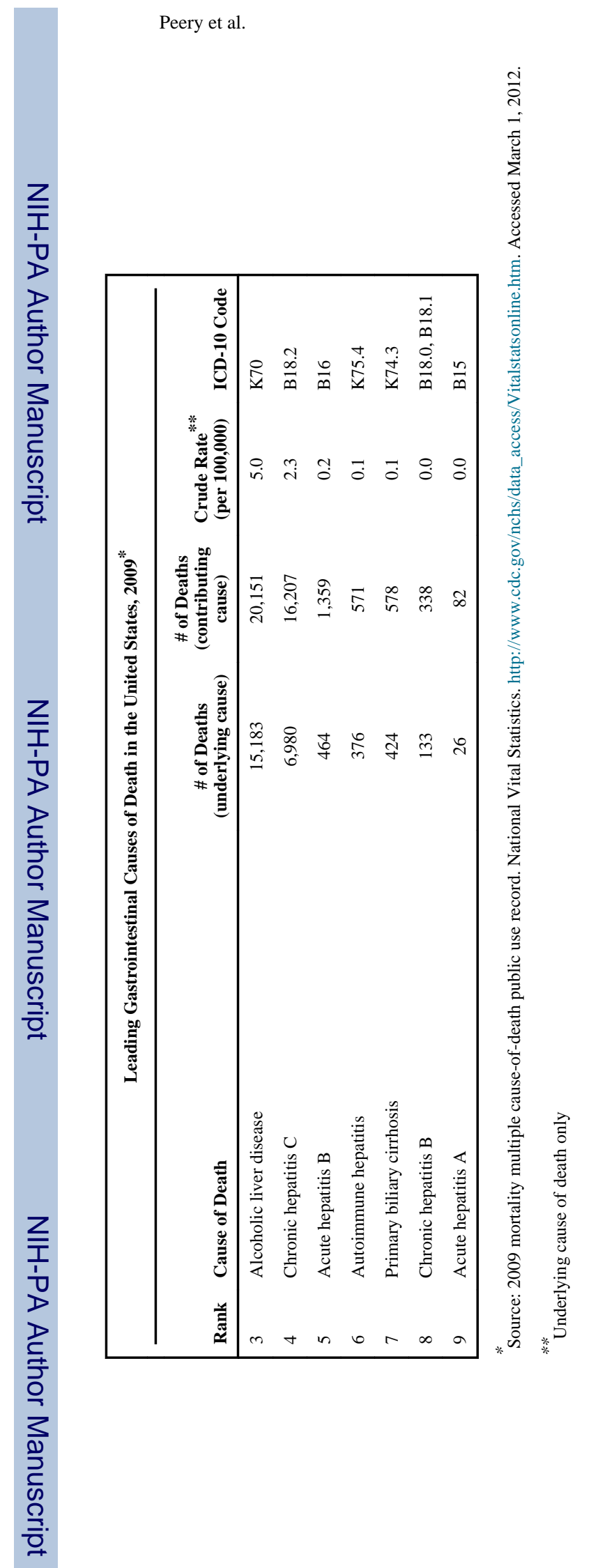

Gastroenterology. Author manuscript; available in PMC 2013 November 01. 


\begin{tabular}{|c|c|c|c|c|c|c|c|c|c|c|c|c|}
\hline ?2 & $\begin{array}{l}0 \\
+ \\
\stackrel{0}{0}\end{array}$ & 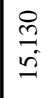 & $\begin{array}{l}\hat{E} \\
\stackrel{0}{\sigma}\end{array}$ & 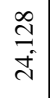 & $\left|\begin{array}{l}0 \\
0 \\
0 \\
\tilde{n} \\
\end{array}\right|$ & 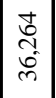 & 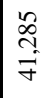 & 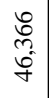 & \begin{tabular}{|l|}
0 \\
0 \\
0 \\
in \\
n.
\end{tabular} & $\mid \begin{array}{c}\mathbf{t} \\
0 \\
i \\
i n\end{array}$ & 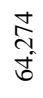 & $\underset{\text { in }}{\stackrel{+}{\stackrel{5}{n}}}$ \\
\hline $\begin{array}{l}\hat{t} \\
\hat{z}\end{array}$ & 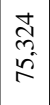 & $\begin{array}{l}\text { o } \\
\text { o } \\
\text { i } \\
\end{array}$ & $\begin{array}{l}\infty \\
\vdots \\
0 \\
0 \\
0 \\
0\end{array}$ & $\begin{array}{l}\tilde{n} \\
\stackrel{2}{2} \\
\end{array}$ & 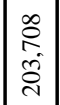 & $\mid \begin{array}{l}0 \\
0 \\
0 \\
\text { î̀ } \\
\text { in }\end{array}$ & $\begin{array}{l}\circ \\
\stackrel{0}{8} \\
\end{array}$ & $\begin{array}{l}\vec{\nabla} \\
\tilde{0} \\
0 \\
0\end{array}$ & $\mid \begin{array}{l}\tilde{2} \\
\hat{\sigma} \\
\hat{\sigma}\end{array}$ & $\mid \begin{array}{l}0 \\
0 \\
0 \\
0 \\
0 \\
0\end{array}$ & $\begin{array}{l}\text { हे } \\
\frac{1}{6}\end{array}$ & ڤे \\
\hline 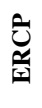 & $\begin{array}{l}\infty \\
\hat{\omega} \\
\hat{\sim} \\
\tilde{\sim}\end{array}$ & 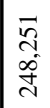 & 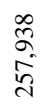 & $\begin{array}{l}\overrightarrow{0} \\
\text { d } \\
\tilde{d} \\
\tilde{N}\end{array}$ & 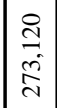 & 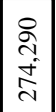 & 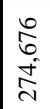 & 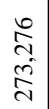 & 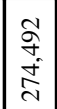 & 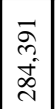 & 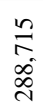 & $\hat{\ddot{\gamma}}$ \\
\hline 워 & 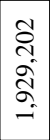 & $\begin{array}{l}n \\
2 \\
\alpha \\
+ \\
0 \\
i \\
i\end{array}$ & 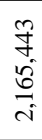 & $\begin{array}{l}n \\
\cong \\
\vec{n} \\
i \\
i\end{array}$ & 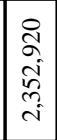 & \begin{tabular}{|c|} 
\\
0 \\
+ \\
$\infty$ \\
0 \\
0 \\
$i$ \\
$i$ \\
\end{tabular} & 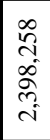 & $\begin{array}{c}\text { oे } \\
\infty \\
o \\
\text { f } \\
\text { i }\end{array}$ & $\begin{array}{l}n \\
\hat{2} \\
\hat{n} \\
\hat{\imath} \\
i\end{array}$ & 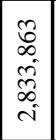 & 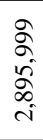 & $\bar{i}$ \\
\hline 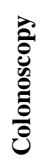 & $\begin{array}{c}n \\
\hat{n} \\
0 \\
0 \\
i\end{array}$ & $\begin{array}{l}\vec{S} \\
\vec{J} \\
i n \\
i\end{array}$ & 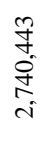 & $\begin{array}{l}\mathscr{c} \\
\tilde{y} \\
b \\
\infty \\
\infty \\
i\end{array}$ & $\begin{array}{l}\infty \\
\infty \\
\infty \\
\infty \\
\\
i\end{array}$ & 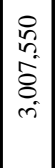 & 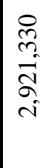 & $\begin{array}{l}\stackrel{\partial}{\infty} \\
\infty \\
\infty \\
\infty \\
i \\
i\end{array}$ & 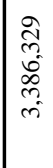 & $\begin{array}{c}\text { के } \\
0 \\
0 \\
\tilde{\omega} \\
\tilde{\omega}\end{array}$ & 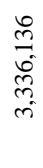 & in \\
\hline 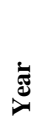 & ષ્ટે & 官 & ठิ & ڤ్రి & ఫ্ণ & 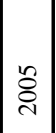 & ¿̊̀ & ڤ్తి & 离 & 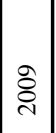 & $\stackrel{\circ}{\stackrel{\sim}{~}}$ & 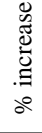 \\
\hline
\end{tabular}

Gastroenterology. Author manuscript; available in PMC 2013 November 01 